\title{
STUDIES ON THE PHYSIOLOGY OF THE PARATHYROID GLANDS
}

\section{Calcium and Phosphorus Studies on a Case of Idiopathic HYPOPARATHYROIDISM}

By FULLER ALBRIGHT AND READ ELLSWORTH

(From the Medical Clinic of the Johns Hopkins Hospital, Baltimore)

(Received for publication December 12, 1928)

\section{INTRODUCTION}

In order to determine, if possible, the exact train of events which lead to a rise in the serum calcium following the injection of a potent parathyroid extract, we undertook the present series of investigations. The subject of this study was an Italian boy on whom the diagnosis of idiopathic hypoparathyroidism was made. The criteria on which such a diagnosis can be based will be discussed below.

The injection of a potent parathyroid extract results in four wellestablished changes and any theory as to the action of a parathyroid extract will have to take cognizance of these four cardinal points. They are:

$a$. Rise in serum calcium (1).

$b$. Rise in urinary calcium excretion (2) (3) (4).

c. Fall in serum phosphorus (5).

$d$. Rise in urinary phosphorus excretion (2) (3).

Removal of the parathyroid glands results in the converse changes, i.e.,

a. Fall in the serum calcium.

$b$. Fall in the urinary calcium excretion.

$c$. Rise in the serum phosphorus.

$d$. Fall in urinary phosphorus excretion.

In addition Albright, Bauer, Ropes, and Aub (3) emphasize the fact that on administration of parathormone, the increase in urinary phosphorus excretion tends to precede the increase in calcium excretion. They further point out that the increased phosphorus appearing in 
the urine must come partly from phosphorus dissolved in body fluids and not entirely from the calcium phosphate of the bones. Inasmuch as the calcium and phosphorus changes are probably not simultaneous, it was apparent that, by reducing the metabolism periods to eight hours instead of three days, as in the investigations above (3), we could follow this sequence of events more accurately (cf. experiment 1 below). Later we had occasion to reduce the period to 1 hour (cf. experiment 2). These shorter periods made it necessary for us to disregard the fecal excretions. This, however, is justifiable, as it has been shown that, following the injection of parathormone, there is a conspicuous alteration in the urinary excretion of calcium and phosphorus, but not in the fecal excretion of these elements (3).

\section{REPORT OF CASE}

We were fortunate in having the opportunity of studying the effect of parathormone on a patient suffering from idiopathic hypoparathyroidism. The clinical aspects of a case with this rather unique diagnosis are of interest.

The patient, a school-boy of 14 of Italian descent, first entered the Medical Service of the Johns Hopkins Hospital on January 17, 1927 for relief of tetany (J. H. H. No. 9974).

The family history was non-contributory.

The past history was uneventful except that he had had measles and chicken pox at 5 years of age.

In 1918, at the age of 5, while under treatment for measles in the Harriet Lane Children's Clinic, it was noted that the patient had markedly hypertrophied tonsils. Tonsillectomy was performed in 1921. Shortly thereafter he began to be troubled at night with attacks of laryngismus. In August, 1922 he had his first attack of carpo-pedal spasm, precipitated by a gastro-intestinal upset. A second attack in January, 1923 was preceded by an upper respiratory infection. Examination at that time at the Harriet Lane Children's Clinic showed carpopedal spasm, a bilateral Chvostek sign, and an injected pharnyx. The cathodal opening contraction was 1.0 milliampere. The serum calcium was $4.9 \mathrm{mgm}$. per $100 \mathrm{cc}$. and the serum phosphorus $10.4 \mathrm{mgm}$. The blood sodium chloride was $560 \mathrm{mgm}$. per $100 \mathrm{cc}$.

Ammonium chloride gave him symptomatic relief. However, the general course of the disease was downhill so that at the time of his first admission to the Medical Service he was having each day about fifteen attacks of carpopedal spasm. The individual attack was as a rule precipitated by some unusual exertion such as crossing the street or stealing a base in a ball-game. Momentary loss of consciousness was frequently associated with the attacks.

Physical examination showed a normally developed Italian boy of healthy 
appearance. The teeth were in poor repair. Both epitrochlear glands were palpable. Chvostek's and Trousseau's signs were positive.

Other examinations showed a red blood cell count of 5,000,000; hemoglobin of 90 per cent (Sahli); white blood cell count 6600 with a normal differential count; a negative Wassermann reaction, a basal metabolism of minus six, and an entirely normal urine. The plasma calcium was $8.0 \mathrm{mgm}$. per $100 \mathrm{cc}$. and the phosphorus $10.9 \mathrm{mgm}$. per $100 \mathrm{cc}$. The whole blood chlorides were $470 \mathrm{mgm}$. per $100 \mathrm{cc}$. and the $\mathrm{CO}_{2}$ combining power 52.4 volumes per cent.

Following the administration of parathormone ${ }^{1}$ there was complete relief. The serum calcium was raised to $16.2 \mathrm{mgm}$. and the serum phosphorus was lowered to $4.7 \mathrm{mgm}$. Symptoms returned, however, in one week after discontinuing parathormone.

The present, the fourth admission to the Medical Service, was on March 21, 1928 for relief for tetany. This time his symptoms had again, as frequently before, been aggravated by a pharyngitis. Examination this time showed; in addition to the signs of tetany, a spleen which was just palpable. Ophthalmoscopic examination revealed a posterior, subcapsular, lenticular opacity and several peripheral, radially distributed, lenticular opacities in the right eye. In the left eye a few lenticular opacities were noted. The serum phosphorus was $10.8 \mathrm{mgm}$. per $100 \mathrm{cc}$. and the serum calcium $5.3 \mathrm{mgm}$. per $100 \mathrm{cc}$. X-rays of the bones revealed nothing abnormal.

The features of this case which make it possible to group it with those of hypoparathyoid tetany are:

$a$. Low serum calcium.

$b$. High serum phosphorus (in direct contradistinction to the infantile type of tetany where the serum phosphorus is low or normal or only slightly elevated).

c. Cataracts, which so commonly occur in post-operative hypoparathyroidism.

$d$. Normal density of bones as shown by X-ray (in contradistinction to instances of tetany associated with rickets and osteomalacia).

$e$. Aggravation of tetany by exertion. We have found this to be characteristic in several cases of tetany of parathyroid origin.

Thus we believe that, just as myxedema is, as a rule, an idiopathic hypothyroidism, so this case represents an idiopathic hypoparathyroidism.

A report of a similar case is soon to be published from the Massachusetts General Hospital (6). This, together with our case, presents exactly converse findings to those of another patient studied at the Massachusetts General Hospital, in whom a diagnosis of idiopathic hyperparathyroidism was made (7).

EXPERIMENT I

Experimental. This investigation lasted twenty-seven days. An effort was made to have all factors as constant as possible. Conse-

${ }^{1}$ Preparation of parathyroid extract introduced by Collip (1) and supplied by the Eli Lilly Company. 


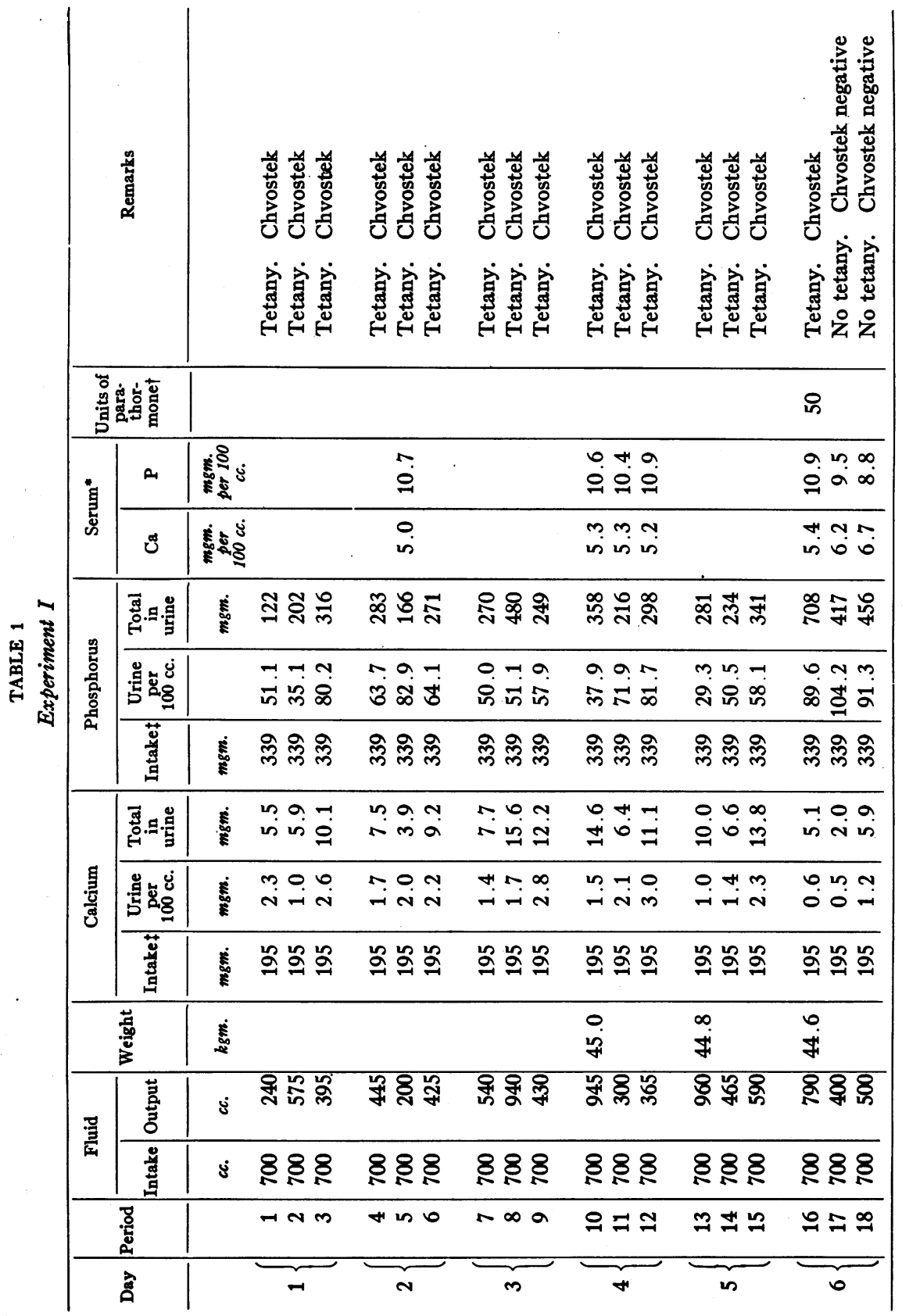




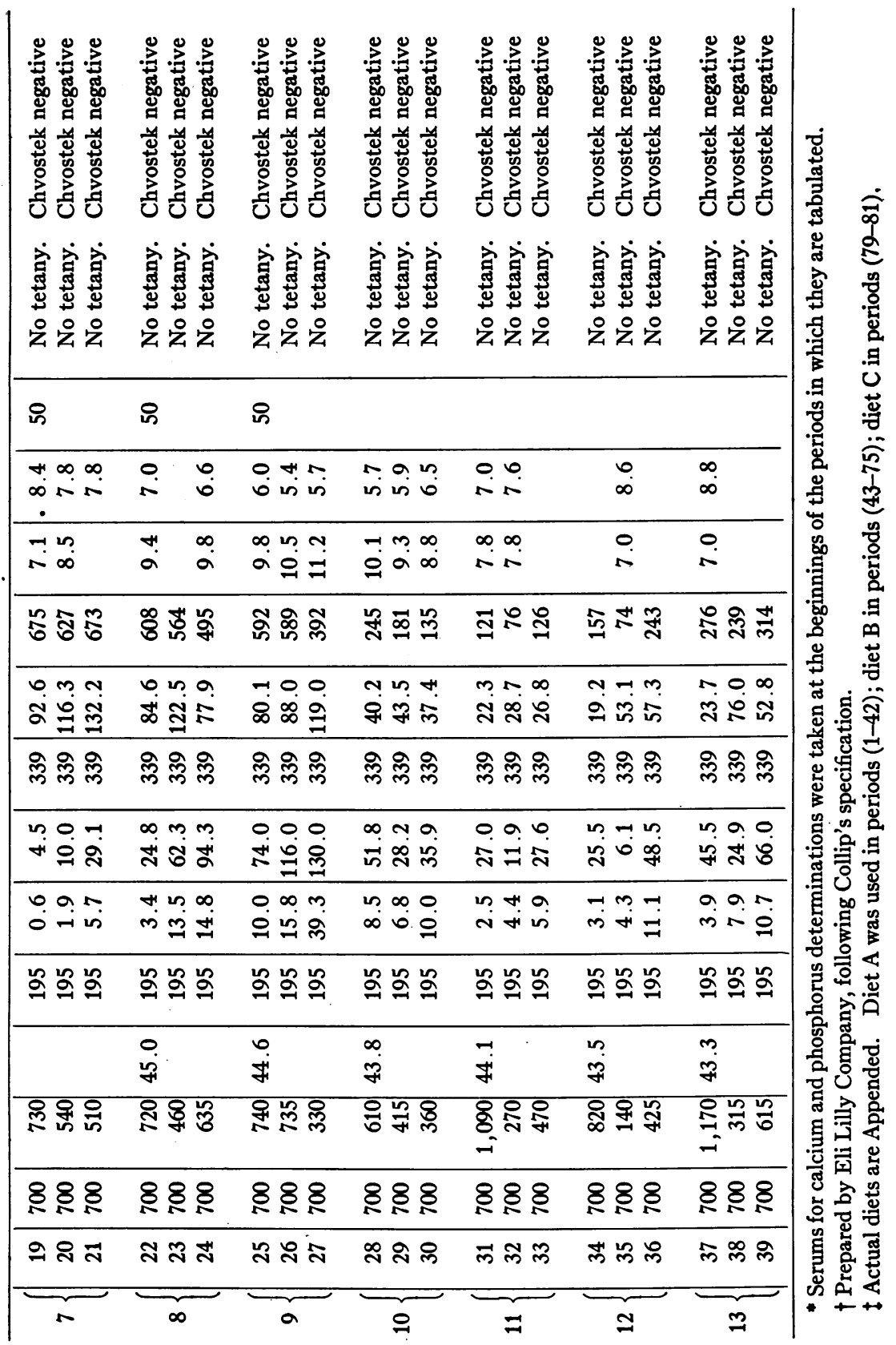




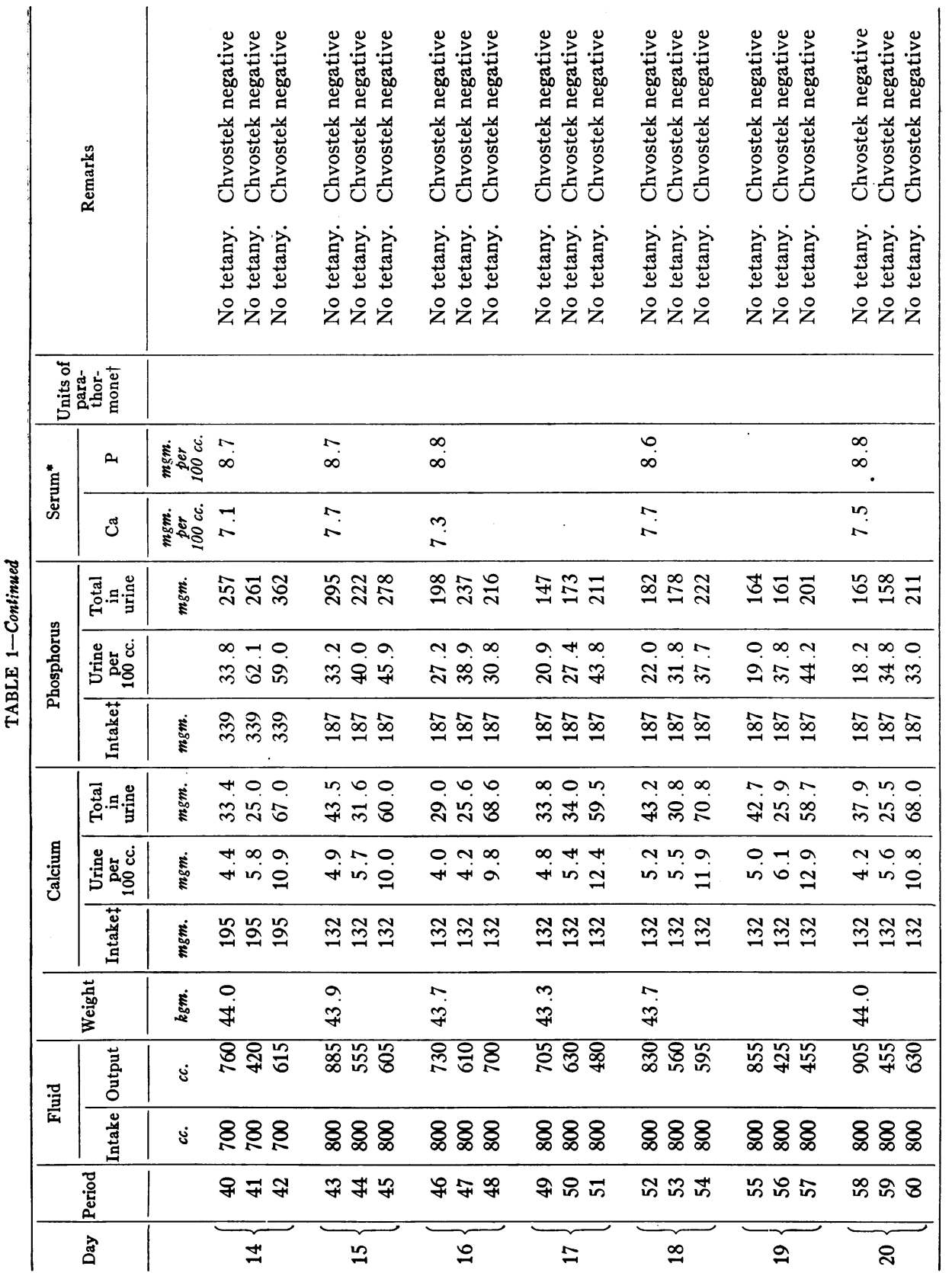




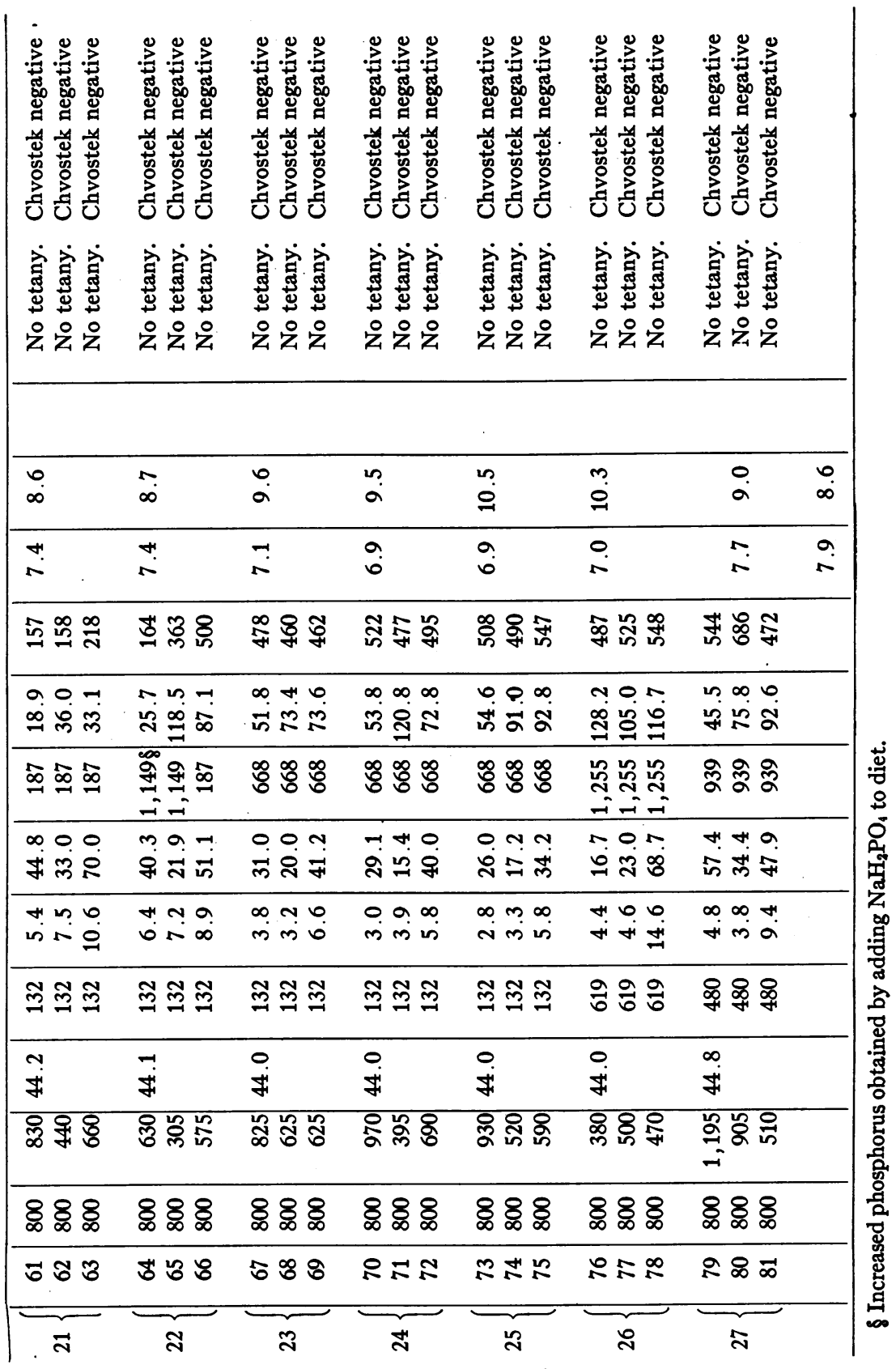


quently the patient was kept in bed and in doors. Each day was divided into three eight-hour metabolism periods. The periods began at 8 a.m., 4 p.m., and 12 midnight. The patient was given the same meal three times a day at the beginning of each period. Water was likewise administered in equal amounts and at the same relative time in each period. The urine was collected for each period and analyzed for calcium ${ }^{2}$ and for phosphorus (9). Vena punctures when done were performed at the beginning of the periods. Fifty units of parathormone were administered at the beginning of periods 16, 19, 22 and 25 (cf. chart 1). The diet was altered at period 43 and several times thereafter as can be noted from table 1. The data for this experiment are given in table 1 and chart 1.

Results. One notes in control periods 1 to 15 before the administration of parathormone a constantly high serum phosphorus, a correspondingly low serum calcium, and extremely low calcium excretion in the urine, and a phosphorus excretion in the urine comparable with that observed in normal persons on a similar phosphorus intake. This normal urinary phosphorus excretion is not at variance with the four cardinal points mentioned above or with the lowered phosphorus excretion following parathyroidectomy, demonstrated by Greenwald (10). In our case the patient was in equilibrium at a constant level of hypoparathyroidism and was not shifting from a normal to a hypoparathyroid state, as in the post-operative cases. On administration of parathormone the urinary phosphorus excretion rose to its maximum, even exceeding the intake, in the first period (period 16), maintained this high level throughout the period of parathormone administration, and then fell abruptly following cessation of parathormone administration. The serum phosphorus fell coincidently with the increased phosphorus excretion and rose again when the phosphorus excretion fell off. The serum calcium rose as the serum phosphorus fell and vice versa with almost no tendency for one to lag behind the other. The calcium excretion failed to rise during the five periods following parathormone administration but then rose very abruptly.

The calcium excretion fell off following cessation of parathormone

${ }^{2}$ Fiske method described by Blackfan and Hamilton (8). 
administration. It should also be noted that the calcium excretion in the urine actually fell slightly during the first five periods after the beginning of parathormone administration. Following cessation of

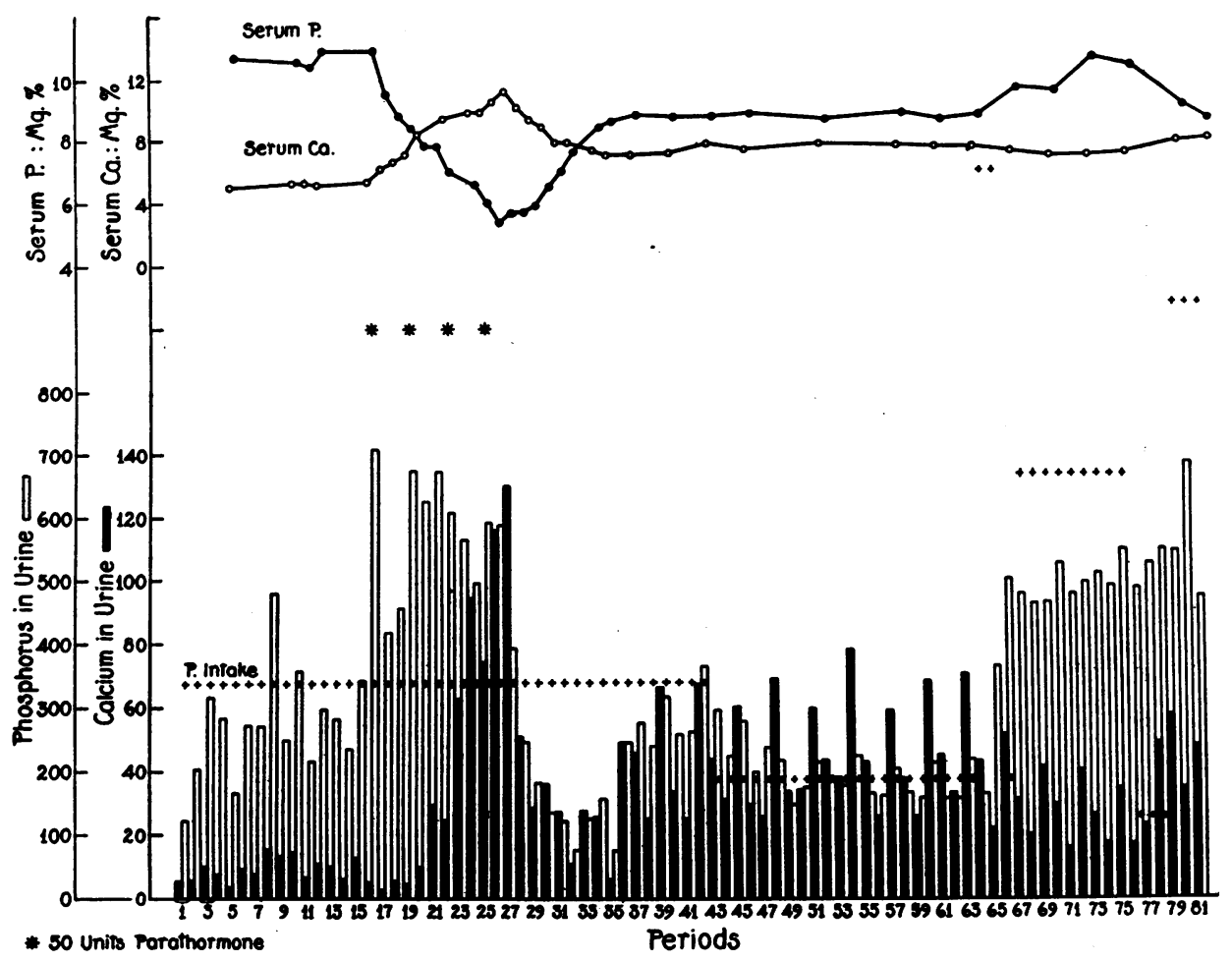

Chart 1. Graphic Representation of Data in Expertment 1

The scale for the serum phosphorus is twice that for the serum calcium. This is so chosen because the normal value for serum calcium is about twice that for serum phosphorus, and because, consequently, a change of $2 \mathrm{mgm}$. of calcium represents the same percentage deviation from normal as a change of one $\mathrm{mgm}$. of phosphorus. For convenience in charting, the scale for the urinary calcium excretion is five times that for the urinary phosphorus excretion. Since the ratio of calcium to phosphorus in bone is 2.23 a calcium scale one-half that of the phosphorus would have been more logical, although not practical.

parathormone administration the phosphorus excretion fell below the preparathormone level of excretion (cf. periods 29 to 35). This is analogous to the decreased phosphorus excretion following parathy- 
roidectomy (10). It may be significant that of these four variables, the phosphorus excretion alone seemed to depend quantitatively on the amount of parathormone given. The others seemed to depend on how long the parathormone was given and perhaps on how long this high level of phosphorus excretion was maintained.

In periods 43 to 63 the phosphorus intake was decreased to a minimum in order to determine whether the serum phosphorus could thus be diminished. The result was a decreased phosphorus excretion with practically no change in the serum phosphorus or in the serum calcium. Likewise in periods 64 to 75 , when the phosphorus intake was greatly increased by the addition of primary sodium phosphate to the diet, the urinary phosphorus excretion was greatly elevated while there was only a slight tendency for the serum phosphorus to rise and for the serum calcium to fall. Periods 76 to 81 will not be discussed as the changes in the diet were too radical.

Comment. The observations of experiment I suggest certain conclusions, the interpretation of which may be as follows:

1. A state of hypoparathyroidism is associated with a fairly normal urinary phosphorus excretion, a very high serum phosphorus, a lowserum calcium, and a very low urinary calcium excretion.

2. Administration of parathormone to an individual in a state of hypoparathyroidism modifies all four of these factors, viz.:

a. The urinary phosphorus excretion immediately rises to its maximum (at least within eight hours).

$b$. Coincidently the serum phosphorus falls.

c. The serum calcium rises.

$d$. The urinary calcium excretion at·first diminishes, and then when . the serum calcium is about 8.5 , suddenly increases.

3. Cessation of administration of parathormone to an individual who had been brought from a hypoparathyroid state to the normal, further modifies these factors, as follows:

$a$. The phosphorus excretion at once falls even below the preparathormone level.

$b$. The serum phosphorus rises.

c. The serum calcium falls.

$d$. The calcium excretion falls, but less precipitously than the phosphorus excretion. 
4. Whereas the urinary calcium excretion ordinarily varies with the height of the serum calcium (3), there seems to be a threshold-level at about $8.5 \mathrm{mgm}$. of calcium per $100 \mathrm{cc}$., below which, the calcium excretion in the urine becomes more or less constant and is independent of the serum calcium value.

TABLE 2

Experiment II

\begin{tabular}{|c|c|c|c|c|c|c|c|c|c|}
\hline \multirow[b]{2}{*}{ 㬝 } & \multirow[b]{2}{*}{ 总 } & \multirow[b]{2}{*}{ 咅 } & \multirow{2}{*}{ 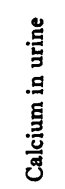 } & \multirow[b]{2}{*}{ 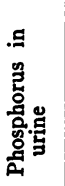 } & \multirow{2}{*}{ 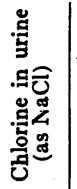 } & \multicolumn{2}{|c|}{ Serum ${ }^{*}$} & \multirow{2}{*}{ 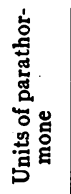 } & \multirow[b]{2}{*}{ Remarks } \\
\hline & & & & & & 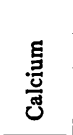 & 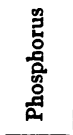 & & \\
\hline a.m. & $c c$. & $c c$. & $m g m$. & $m g m$. & grams & $\begin{array}{c}\text { mgm. } \\
\text { per } \\
100 \mathrm{cc} .\end{array}$ & $\begin{array}{c}\text { mgm. } \\
\text { per } \\
100 \text { cc. }\end{array}$ & & \\
\hline $7-8$ & 250 & 85 & 2.8 & 7.2 & 0.59 & & & & $\begin{array}{l}\text { Serum } \mathrm{CO}_{2} 51.3 \text { volumes per } \\
\text { cent. Serum NaCl } 597 \text { mgm. } \\
\text { per } 100 \mathrm{cc} \text {. Refractive in- } \\
\text { dex } 1.3530\end{array}$ \\
\hline $8-9$ & 250 & 185 & 1.4 & 6.2 & 0.50 & 7.3 & & & \\
\hline $9-10$ & 250 & 230 & 1.7 & 6.4 & 0.69 & & & & \\
\hline $10-11$ & 250 & 255 & 1.6 & 6.9 & 0.48 & 7.5 & 10.3 & & \\
\hline $11-12$ & 250 & 510 & 3.3 & 39.5 & 1.07 & & & 75 & \\
\hline p.m. & & & & & & & & & \\
\hline $12-1$ & 250 & 270 & 0.9 & 72.0 & 0.32 & 7.3 & 10.2 & & \\
\hline $1-2$ & 250 & 220 & 1.0 & 62.7 & 0.20 & 7.5 & & & \\
\hline $2-3$ & 250 & 230 & 1.0 & 58.0 & 0.21 & 7.7 & 8.8 & & \\
\hline $3-4$ & 250 & 275 & 0.8 & 73.7 & 0.28 & 8.1 & 9.3 & & \\
\hline $4-5$ & 250 & 85 & 0.5 & 72.9 & 0.32 & 8.7 & 9.2 & & \\
\hline 5-6 & 250 & 240 & 1.1 & 33.1 & 0.22 & & & & $\begin{array}{l}\text { Serum } \mathrm{CO}_{2} 52.2 \text { volumes per } \\
\text { cent. Serum } \mathrm{NaCl} 591 \mathrm{mgm} \text {. } \\
\text { per } 100 \mathrm{cc} \text {. Refractive in- } \\
\text { dex of serum } 1.3532\end{array}$ \\
\hline $6-7$ & & & & & & 8.0 & 9.3 & & \\
\hline
\end{tabular}

* Blood for $\mathrm{Ca}$ and $\mathrm{P}$ taken at beginning of period tabulated.

5. The high serum phosphorus, present in hypoparathyroidism, does not appear to be altered materially in a week's time either by a very low phosphorus intake or by a very high one.

\section{EXPERIMENT II}

The impression has been prevalent that parathormone is a drug that acts slowly. Collip (1) points out that when parathormone is in- 
jected into dogs the peak of the serum calcium curve is reached in twelve to twenty-four hours. In experiment I, we have shown that the maximum effect on urinary phosphorus excretion was reached

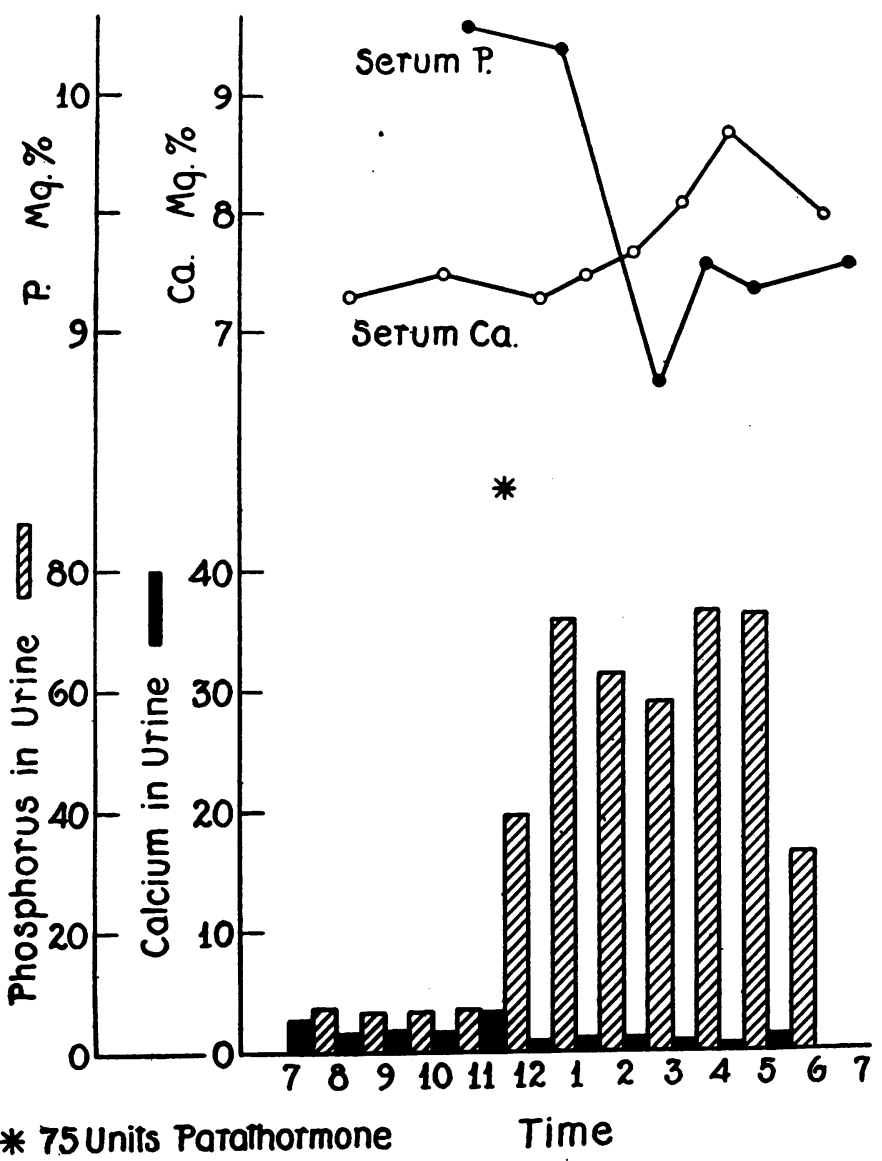

Chart 2. Graphic Representation of Calcium and Phosphorus DATA IN EXPERIMENT 2

The scale for the serum phosphorus is twice that for the serum calcium. The scale for the phosphorus excretion in the urine is one-half that of the calcium excretion.

somewhere during the first eight hours. The second experiment was planned to determine whether this increased phosphorus excretion might occur even earlier than eight hours. 
Experimental. Following a period of 16 days on a low phosphorus diet ( 0.345 gram per day), the patient fasted and remained in bed for the day of the experiment. He received $250 \mathrm{cc}$. of water at $7 \mathrm{a}$ am. and the same amount every hour thereafter until 6 p.m. when the investigation ceased. The urine was collected every hour and analyzed for calcium, phosphorus and chlorine. At 11 a.m. 75 units of parathormone were administered. The results can be seen in table 2 and chart 2.

Results. It will be noted that the excretion of urinary phosphorus increased about 500 per cent in the first hour after parathormone administration and reached its peak by the second hour. In this experiment the serum phosphorus seems to have fallen more quickly than the serum calcium rose. Both of these values had altered within three hours of the injection. The calcium excretion was slightly decreased following the injection (cf. experiment I). The increased excretion of water and sodium chloride in the first hour after injection are interesting but will not be discussed here.

Comment. 6. The action of parathormone on the excretion of urinary phosphorus is maximal within the first hour after injection. It follows from this that future studies must concentrate on the changes occurring in the first hour after injection if one is to learn the fundamental mechanism, - not the remote end-results.

\section{EXPERIMENT III}

In the latter part of experiment $I$ it was noted that changes in the amount of phosphorus in the diet had little effect on the serum phosphorus. It was desired to extend this investigation over longer periods of time because of its important theoretical significance.

Experimental. This experiment started immediately after experiment I and lasted forty days. The time was divided into 10 four-day metabolism periods. During the first six periods the patient was on a high phosphorus diet (1.756 gram per day) and during the remaining four on a low phosphorus diet ( 0.345 gram per day). Except for the change from the high to the low phosphorus diet, the patient received the same food each day. He likewise received the same amount of water each day. He was not kept in bed. The urine for each period was examined for calcium, phosphorus and nitrogen, and the feces 


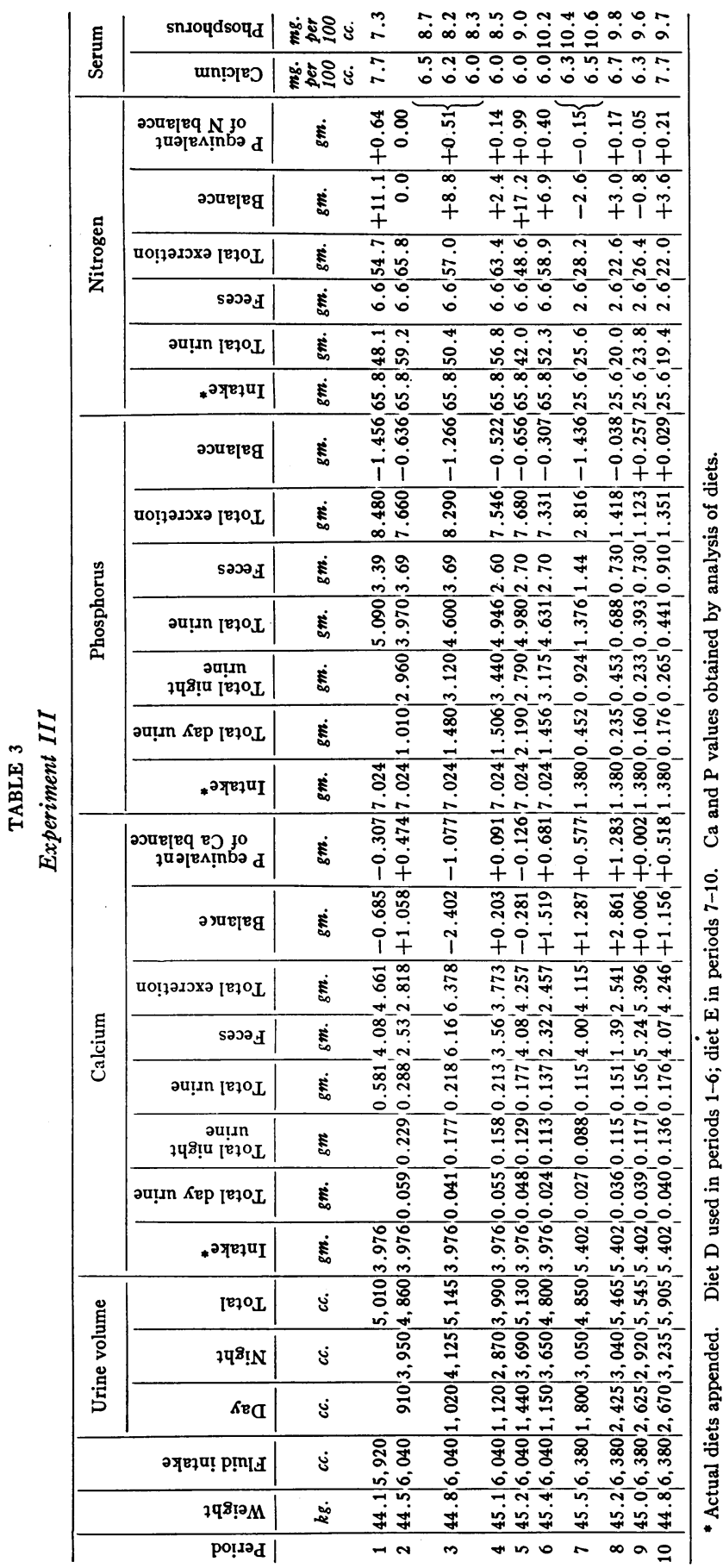

196 


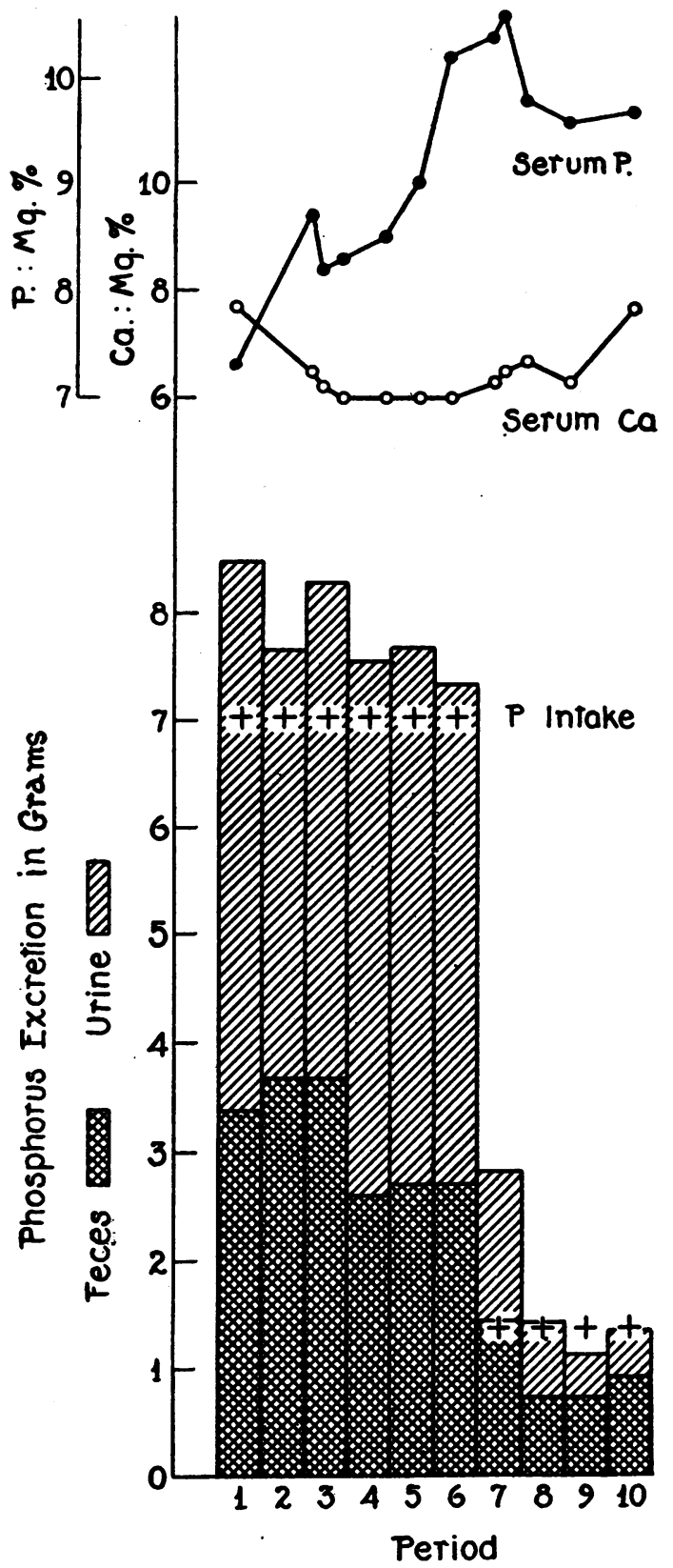

Chart 3. Graphic Representation of Phosphorus Metabolism in EXPERIMENT 3 
for calcium and phosphorus. ${ }^{3}$ Furthermore, after period 1, because of certain marked discrepancies which were at once noted, the day urine ( 7 a.m. to 7 p.m.) was collected and analyzed separately from the night urine. The results are shown in table 3 and chart 3 .

Results. Before drawing any conclusions regarding the phosphorus balance, we might have made allowance for the phosphorus deposited with the protein in muscle and with the calcium in bones (11). However, examination of the calcium and nitrogen balances shows that these factors are smaller than the probable errors of the investigation. Also, it is true that too much reliance cannot be placed upon balance columns where very high intakes are involved, because a small percentage error in the intake would make a considerable error in the balance. Even so, although the serum phosphorus did rise considerably, it is quite apparent from the phosphorus balances (table 3) that, during the first six periods, while on a high phosphorus intake, the patient's kidneys had little difficulty in excreting phosphorus. Furthermore, when the phosphorus intake was suddenly lowered the excretion of urinary phosphorus fell immediately rather than slowly, as it would, had there been any previous difficulty in excreting phosphorus.

The marked polyuria at night (table 3 ) was very striking, especially during the first six periods It is also of interest that there was a relative increase in the urinary excretion of calcium, phosphorus, and nitrogen at night proportional to the increased excretion of water. Like the polyuria noted in experiment II in the first hour following parathormone injection, these will have to remain as isolated observations for the time being. They lead one to suspect some abnormality in the water balance.

Comment. 7. At any given level of hypoparathyroidism there was no marked difficulty in excreting phosphorus nor could the blood chemistry be markedly altered by high and low phosphorus diets.

\section{DISCUSSION}

The serum calcium and serum phosphorus curves in experiment I certainly suggest that one ion rises because the other falls or vice

\footnotetext{
${ }^{3}$ We are much indebted to Dr. Joseph C. Aub and his associates at the Massachusetts General Hospital for having the feces analyzed for us.
} 
versa. One cannot escape the idea that this relationship is dependent on the ability of the serum to hold calcium phosphate, and that, in the presence of normal bones, the blood calcium contains all the calcium and phosphorus ions which its physical state will permit. It also seems almost certain that the increased phosphorus excretion, the increased calcium excretion, the decreased serum phosphorus, and the increased serum calcium following parathormone administration are four interrelated facts.

Our work, together with that of Albright, Bauer, Ropes, and Aub (3) suggests the following tentative hypothesis as to the modus operandi.

When parathormone is administered, the equilibria of the body fluids are upset in such a way that an increased phosphorus excretion is a necessary result. We do not know the cause of the increased phosphorus excretion, but as a result of this increased phosphorus excretion the body fluids become depleted in phosphorus. The falling serum phosphorus is evidence of this. As the phosphorus and consequently the phosphate ions in the serum fall, there is a tendency to an unsaturation of the blood with calcium phosphate. This tendency is met by a mobilization of calcium phosphate from the bones. Thus a deficit in phosphate ions is being supplied by calcium and phosphate ions. Consequently the serum calcium rises. With a rise in the serum calcium, provided the level is not below the threshold for calcium excretion, there is a rise in urinary calcium output.

The sequence of events which takes place after parathormone administration (chart 1) strongly supports such an hypothesis, except that we have been unable to show consistently that the fall in serum phosphorus precedes, by any detectable interval, the rise in serum calcium.

It may be that the calcium-phosphorus equilibrium is so finely adjusted that we have not been able to detect the small initial change, or possibly we have not yet studied short enough periods.

On the basis of our hypothesis, the question immediately arises as to what causes the increased phosphorus excretion after parathormone injection. It seemed at first that there might be a specific impairment of renal function in hypoparathyroidism whereby phosphorus excretion was inhibited. However, in experiment III, the 
high phosphorus excretion during a high phosphorus diet and the immediate fall to a low phosphorus excretion when the diet was changed to one low in phosphorus would seem to disprove this. All that we can say, therefore, is that some change in the blood equilibria occurs as the result of parathormone administration which makes necessary this increased phosphorus excretion.

SUMMARY AND CONCLUSIONS

1. The clinical aspects of a case of idiopathic hypoparathyroidism are reported.

2. The criteria on which the diagnosis of idiopathic hypoparathyroidism is made.are:

a. Low serum calcium.

$b$. High serum phosphorus.

c. Cataract.

$d$. Normal density of bones by $\mathrm{x}$-ray.

$e$. Aggravation of tetany by exertion.

3. Following the injection of an active parathyroid extract, an increase in phosphorus excretion was immediately detectable and reached its maximum within the first two hours. The mechanism of this is not apparent from our data.

4. Evidence is educed from study of the metabolism of the patient to show that the increase in serum calcium, the increase in calcium excretion, and the decrease in serum phosphorus following parathormone administration may all be the sequelae of this increase in phosphorus excretion.

5. An hypothesis is suggested to explain these interrelationships.

6. By using high and low phosphorus diets, it seems that there is no inability to excrete phosphorus in hypoparathyroidism and it follows, therefore, that the increased excretion of phosphorus following injection of parathormone is not due to an increase in the excretory ability of the kidney for this element.

7. As the serum caicium rose from 5.2 to $11.2 \mathrm{mgm}$. per $100 \mathrm{cc}$. following the injection of parathormone there was a critical serum calcium value of about 8.5 , at which point an almost negligible urinary calcium excretion suddenly changed to a very appreciable one. When the serum calcium was above 8.5 the urinary calcium increased as the 
serum calcium rose then decreased abruptly as soon as the serum calcium fell below $8.5 \mathrm{mgm}$. per $100 \mathrm{cc}$. This suggests that there is a threshold for urinary calcium excretion and that this threshold is below the normal value for serum calcium.

We wish to express our gratitude to Miss M. Struve for her assistance in arranging diets and superintending the collection of specimens.

\section{BIBLIOGRAPHY}

1. Collip, J. P., Medicine, 1926, v, 1. The Parathyroid Glands.

2. Greenwald, I., and Gross, J., J. Biol. Chẹm., 1926, lxviii, 325. The Effect of Long Continued Administration of Parathyroid Extract upon the Excretion of Phosphorus and Calcium.

3. Albright, F., Bauer, W., Ropes, M., and Aub, J. C., J. Clin. Invest. 1929, vii, 139. Studies of Calcium and Phosphorus Metabolism. IV. The Effects of the Parathyroid Hormone.

4. Hunter, Donald, and Aub, J. C., Quart J. Med., 1927, xx, 123. Lead Studies. XV. The Effect of the Parathyroid Hormone on the Excretion of Lead and of Calcium in Patients Suffering from Lead Poisoning.

5. Albright, F., and Bauer, W., The Effect of the Parathyroid Hormone on the Relation of Serum Calcium to Serum Phosphorus. To be published.

6. Bauer, W., Albright, F., Rossmeisl, E., Aub, J. C., Studies of Calcium and Phosphorus Metabolism. The Calcium and Phosphorus Metabolism in Tetany with Observations on the Therapeutic Action of Thyroid and Ammonium Chloride Medication. To be published.

7. Bauer, W., and Albright, F., Studies of Calcium and Phosphorus Metabolism. A Case of Supposed Hyperparathyroidism with Thyroidectomy. To be published.

8. Blackfan, K. D., and Hamilton, B., Johns Hopkins Hosp. Bull., 1927, xli, 322. Study of the Inorganic Constituents of Serum in Children with Acute Nephritis.

9. Benedict, S. R., and Theis, R., J. Biol. Chem., 1924, lxi, 63. A Modification of the Molybdic Method for the Determination of Inorganic Phosphorus in Serum.

10. Greenwald, I., and Gross, J., J. Biol. Chem., 1925, lxvi, 185. The Effect of Thyroparathyroidectomy in Dogs upon the Excretion of Calcium, Phosphorus, and Magnesium.

11. Bauer, W., Albright, F., and Aub, J. C., J. Clin. Invest., 1929, vii, 75. Studies of Calcium and Phosphorus Metabolism. II. The Calcium Excretion of Normal Individuals on a Low Calcium Diet including Data on a Case of Pregnancy. 